\title{
ANÁLISE DA VULNERABILIDADE NATURAL PARA IMPLANTAÇÃO DE UNIDADES DE CONSERVAÇÃO NA MICRORREGIÃO DA SERRA DE CARRANCAS, MG
}

\author{
Ludimilla Portela Zambaldi Lima¹, Júlio Louzada², Luís Marcelo Tavares de Carvalho³, \\ José Roberto Soares Scolforo ${ }^{4}$
}

(recebido: 25 de março de 2009; aceito: 28 de janeiro de 2011)

\begin{abstract}
RESUMO: A implantação de Unidades de Conservação tem sido uma das melhores formas de conservação da biodiversidade. Regiões de maiores altitudes como as da Serra de Carrancas e Luminárias, em Minas Gerais, possuem características físicas e bióticas que fazem destes ambientes detentores de espécies endêmicas e alta biodiversidade. Entretanto, são ambientes altamente susceptíveis aos processos erosivos acelerados, o que ocasiona a perda de solo, hábitat e espécies. Objetivou-se, com o presente estudo, avaliar as características físicas e bióticas da região da Serra de Carrancas e Luminárias através de indicadores da Vulnerabilidade Natural e propor a implantação de uma Unidade de Conservação em regiões que são, consideradas por este índice, locais de elevada importância ambiental e que são altamente sensíveis às ações antrópicas. Os indicadores bióticos e abióticos gerenciados em um sistema de informações geográficas delimitaram áreas de maior vulnerabilidade na área de estudo e, devido à sensibilidade e abrangência áreas de maior vulnerabilidade na área de estudo e, devido à sensibilidade e abrangência da Serra de Carrancas e Luminárias, foi proposta a implantação de um Parque Estadual. O índice de vulnerabilidade natural se mostrou uma ferramenta eficiente na indicação de áreas a serem conservadas, reunindo fatores ambientais importantes, aumentando a eficiência das estratégias de conservação.
\end{abstract}

Palavras-chave: SIG, Zoneamento Ecológico Econômico, biodiversidade, indicador.

\section{VULNERABILITY ANALYSIS FOR IMPLEMENTATION OF CONSERVATION UNITS IN THE SERRA DE CARRANCAS MICROREGION, MG}

ABSTRACT: Conservation Units are among the best methods found to secure biodiversity conservation. The physical and biotic characteristics of high altitude areas such as Serra de Carrancas and Luminárias, in Minas Gerais state, make these places a home to endemic species and to rich biodiversity. However, these environments are highly susceptible to fast advancing erosive processes that potentially lead to soil, habitat and species loss. This study aims to evaluate the physical and biotic characteristics of the Serra de Carrancas and Luminárias region using Natural Vulnerability indicators, and also to propose Conservation Unit implementation in areas which, as per this index, are considered environmentally critical and highly sensitive to anthropic actions. Biotic and abiotic indicators, as managed by a geographic information system, identified the most vulnerable areas in the study site and, given the sensitivity and scope of Serra de Carrancas and Luminárias, a State Park was proposed. The natural vulnerability index proved to be an effective tool to pinpoint prospective conservation unit areas, gathering important environmental factors and thus improving the efficiency of conservation strategies.

Key words: SIG, Ecological-Economic Zoning, biodiversity, indicator.

\section{INTRODUÇÃo}

A cada dia, aumenta a necessidade de se estabelecerem prioridades de investimento em estratégias conservacionistas para a efetiva preservação dos remanescentes de vegetação nativa ainda existentes no sudeste brasileiro. Entre as estratégias de conservação de maior êxito em escala local, regional e global, está o estabelecimento de Unidades de Conservação (VASCONCELLOS, 2002). Na região sul de Minas Gerais, têm ocorrido modificações nos ecossistemas nativos, que podem chegar a limites extremos de uso da paisagem (OLIVEIRA-FILHO et al., 2004). Desconsiderando-se as espécies de ampla distribuição, estas áreas apresentam poucas espécies em comum com outras serras ao longo da Cadeia do Espinhaço (MG) e da Chapada Diamantina (BA). O mesmo é observado em relação ao Distrito Federal e à Chapada dos Veadeiros (GO) (MATSUMOTO; MARTINS, 2005). Esse fato evidencia a possibilidade de ocorrência de espécies endêmicas de vários grupos taxonômicos na região, reforçando a necessidade de conservação.

\footnotetext{
${ }^{1}$ Bióloga, Doutoranda em Ecologia Aplicada - Departamento de Biologia - Universidade Federal de Lavras - Cx. P. 3037 - $37200-000$ - Lavras, MG ludzambaldi@hotmail.com

${ }^{2}$ Biólogo, Professor Dr. em Entomologia - Departamento de Biologia - Universidade Federal de Lavras - Cx. P. 3037 - $37200-000$ - Lavras, MG jlouzada@dbi.ufla.br

${ }^{3}$ Engenheiro Florestal, Professor Dr. em Geociências e Ambiente - Departamento de Ciências Florestais - Universidade Federal de Lavras - Cx. P. 3037 37200-000 - Lavras, MG - passarinho@dcf.ufla.br

${ }^{4}$ Engenheiro Florestal, Professor Doutor em Engenharia Florestal - Departamento de Ciências Florestais - Universidade Federal de Lavras - Cx. P. 3037 37200-000 - Lavras, MG - scolforo@dcf.ufla.br
} 
Uma das formas de planejamento conservacionista do espaço territorial é o estabelecimento de Áreas Prioritárias para Conservação. Entretanto, este planejamento tem seguido critérios relativamente subjetivos, baseados principalmente em opinião de consultores ad hoc, reunidos em workshops específicos e auxiliados pela parca literatura disponível. Faz-se necessário o estabelecimento de critérios técnicos mais objetivos que possam se somar aos conhecimentos subjetivos do grupo de pesquisadores consultores.

Entre as áreas prioritárias para conservação apontadas pela Fundação Biodiversitas (DRUMMOND et al., 2005) para o estado de Minas Gerais, está a região formada pelo complexo da Serra de Carrancas e Luminárias. Esta serra é composta por áreas de grandes altitudes (entre 970 e $1800 \mathrm{~m}$ ), solos rasos e cobertura vegetal predominantemente campestre. O complexo possui formações rupestres, que recobrem grande extensão da serra e parecem ser uma das últimas ocorrências desta fisionomia no limite sul de distribuição dos campos rupestres brasileiros (CARVALHO, 1992).

A floresta semidecídua alto-montana, na região do município de Carrancas, é considerada uma das áreas de maior relevância de conservação da biodiversidade no Estado de Minas Gerais, por apresentar alta biodiversidade vegetal e protegerem as nascentes de rios significativos da região (OLIVEIRA-FILHO; FLUMINHAN-FILHO, 1999). A região de estudo está localizada numa área de transição entre cerrado e mata atlântica, representando uma região de transição ecológica considerada áreas de elevada importância natural. Por reunir características ecológicas consideráveis somadas à representatividade e extensão, a Serra de Carrancas pode ser considerada um sistema propício à implantação de um Parque Estadual.

A identificação da vulnerabilidade natural de uma área é uma abordagem que proporciona um conhecimento da situação atual do meio ambiente que pode ser tomado como ponto de partida para se atingir o desenvolvimento de forma racional, preservando áreas de maior relevância ambiental. Entende-se como vulnerabilidade natural a incapacidade de uma unidade espacial resistir e/ou recuperar-se após sofrer impactos decorrentes de atividades antrópicas consideradas normais, isto é, não passíveis de licenciamento ambiental pelo órgão competente (SCOLFORO et al., 2008). A vulnerabilidade natural é um índice proveniente do Zoneamento Ecológico-Econômico de Minas Gerais, uma das ações implementadas pelo Governo de Minas Gerais visando à elaboração de um diagnóstico dos meios geo-biofísicos, disponibilizados em um banco de dados espacializados (SCOLFORO et al., 2008).

Com o uso de ferramentas de Sistemas de Informações Geográficas (SIG), é possível criar um diagnóstico ambiental de áreas associando-se aspectos bióticos e abióticos, de modo a inferir sobre o quanto a paisagem é vulnerável à degradação ambiental. As análises feitas por meio de SIG tornam possível evidenciar as áreas críticas que necessitam ser incluídas em Unidades de Conservação de proteção integral das áreas que deveriam ser poupadas (SAMPLE, 1994).

No intuito de contribuir para o ordenamento territorial da área prioritária para conservação Serra de Carrancas e Luminárias, objetivou-se com este trabalho, verificar a vulnerabilidade natural da região e, baseado nesta vulnerabilidade natural, propor o posicionamento ideal para a implantação de uma Unidade de Conservação. Indicadores bióticos e abióticos de Vulnerabilidade Natural permitirão identificar áreas que reúnam características naturais relevantes e que apresentem menor resistência e resiliência às ações antrópicas, delimitando regiões naturais representativas naturalmente e que devam ser conservadas.

\section{MATERIAL E MÉTODOS}

\subsection{Obtenção de dados e unidade de estudo}

Foram utilizadas, neste trabalho, cartas de vulnerabilidade natural à erosão, da fauna, da vegetação e do solo, que compuseram em conjunto a carta de vulnerabilidade natural, proveniente do Zoneamento Ecológico-Econômico do Estado de Minas Gerais (ZEE - MG) (SCOLFORO et al., 2008). Os dados utilizados para compor as cartas de vulnerabilidade originaram-se do tratamento de fontes secundárias de dados, considerando aspectos bióticos extraídos de levantamentos e estudos realizados sobre a flora e a fauna de Minas Gerais, bem como aspectos físicos obtidos a partir da compilação de uma série de publicações sobre solos, relevo, geologia e água (SCOLFORO et al., 2008). A carta de vulnerabilidade natural foi dividida em classes, indicando áreas de maior ou de menor resistência ou resiliência à atividades antrópicas (Tabela 1).

Foi utilizado também o mapa de distribuição de fitofisionomias digitalizado proveniente do Mapeamento e do Inventário da Flora Nativa e dos Reflorestamentos de Minas Gerais (SCOLFORO; CARVALHO, 2006).

Cerne, Lavras, v. 17, n. 2, p. 151-159, abr./jun. 2011 
Tabela 1 - Classes de vulnerabilidade natural, restrições quanto ao uso dos recursos e o grau de impacto sugerido à implantação de algum empreendimento antrópico.

Table 1 - Natural vulnerability classes, restrictions to use of resources and degree of impact suggested, concerning implementation of an anthropic enterprise.

\begin{tabular}{lcc}
\hline $\begin{array}{l}\text { Vulnerabilidade } \\
\text { Natural }\end{array}$ & Restrições & Empreendimento \\
\hline Muito Alta & Sérias & Sem Impacto \\
Alta & Consideráveis & Menor impacto possível \\
Média & Moderadas & Sem danos potenciais \\
Baixa & Baixas & Baixo impacto potencial \\
Muito Baixa & Quase nulas & Com impactos \\
\hline
\end{tabular}

Fonte: Scolforo et al. (2008)

Os dados provenientes das cartas foram estruturados em um sistema de informações geográficas usando o modelo espacial de dados matricial conhecido como raster (BURROUGH; MCDONNEL, 1998). Nesse modelo, considera-se que o espaço pode ser dividido em unidades quadradas contíguas cobrindo uma determinada área na superfície da Terra, chamadas células ou pixels. Toda informação foi considerada completamente homogênea dentro de cada célula da matriz e, portanto, recebeu um único valor para cada atributo que caracterizou a área. Os dados foram empregados em duas etapas. Na primeira etapa, cada carta foi dividida em células de 30 x 30m como base para o cálculo dos indicadores de vulnerabilidade para cada aspecto ecológico avaliado. A segunda etapa constou da ponderação dos indicadores e da geração de cartas dos aspectos ecológicos em células de 270 X 270m. Os aspectos avaliados foram: integridade da flora, integridade da fauna, suscetibilidade do solo à degradação ambiental e suscetibilidade do solo à erosão.

\subsection{Vulnerabilidade biótica}

\subsubsection{Integridade da flora}

Os cálculos dos indicadores foram efetuados comparando-se a contagem de células, na base original do Instituto Estadual de Florestas (IEF) (30x30m), que estavam contidas em cada célula da base do Zoneamento Ecológico-Econômico de Minas Gerais (ZEE-MG) (270x270m). Para o indicador prioridade de conservação da flora, foi feita uma reclassificação das áreas prioritárias à conservação da flora (DRUMMOND et al., 2005). Os indicadores avaliados na integridade da flora foram: Indicador 1. Relevância Regional: é a razão entre área atual de sistemas herbáceo-arbustivos em uma célula e a área total destes ecossistemas na regional do Conselho de Política Regional (COPAM), peso 8; Indicador 2. Grau de Conservação da Vegetação: total de vegetação nativa de uma célula, peso 12; Indicador 3. Heterogeneidade Espacial de Fitofisionomias: para cada célula, foi obtido o número de fisionomias distintas presentes, peso 4; Indicador 4. Prioridade para Conservação da Flora, com peso 12: corresponde à perda futura de vegetação nativa. Para o indicador prioridade de conservação da flora, foi feita uma reclassificação das áreas prioritárias à conservação da flora (DRUMMOND et al., 2005)

\subsubsection{Integridade da Fauna}

A base de dados utilizada para este aspecto foi o Atlas de Áreas Prioritárias de Conservação de Minas Gerais (DRUMMOND et al., 2005). Nesta base, estão apresentadas áreas prioritárias para a conservação de aves, mamíferos, répteis, anfíbios e invertebrados. Foi feita uma reinterpretação do sistema de classificação utilizado pelo atlas, e construído um mapa de vulnerabilidade para cada grupo faunístico. As classes de priorização de conservação especial, extrema e muito alta obtidas pelo atlas foram convertidas na classe muito alta de vulnerabilidade do aspecto integridade da fauna. A classe alta de prioridade de conservação permaneceu alta na classificação de vulnerabilidade. Prioridade de conservação potencial foi convertida em vulnerabilidade média e, para as regiões não classificadas pelo atlas, a classe de vulnerabilidade baixa foi atribuída. Cada indicador (grupo faunístico) recebeu peso idêntico a 20.

\subsection{Vulnerabilidade abiótica}

\subsubsection{Suscetibilidade de solos à degradação ambiental}

Na avaliação deste aspecto, mapas auxiliares foram produzidos: teor de matéria orgânica e textura (CENTRO TECNOLÓGICO DE MINAS GERAIS - CETEC, 2006) e posteriormente reinterpretados, gerando mapas dos indicadores: susceptibilidade do solo à degradação estrutural (peso 10); taxa de decomposição da matéria orgânica do solo (peso 20) e probabilidade de contaminação ambiental pelo uso do solo (peso 30).

\subsubsection{Susceptibilidade de solos a erosão}

Os indicadores avaliados neste aspecto foram: erodibilidade dos solos, baseados no declive das áreas (peso 20) e cobertura vegetal (peso 10), considerando o declive e a exposição do solo na avaliação destes indicadores.

Cerne, Lavras, v. 17, n. 2, p. 151-159, abr./jun. 2011 


\subsection{Categorização das áreas}

A vulnerabilidade natural de cada célula da região de estudo (Serra de Carrancas e Luminárias) foi obtida através da sobreposição ponderada de cartas de vulnerabilidade à erosão, da fauna, da vegetação e do solo. Cada célula do mapa resultante foi rotulada como sendo pertencente a uma das seguintes categorias: Vulnerabilidade Muito Alta, Alta, Média, Baixa e Muito Baixa. Na determinação da vulnerabilidade do sistema, todas as informações foram reclassificadas e combinadas de acordo com essas classes, de forma ponderada, avaliando a importância de cada aspecto físico e biótico para a vulnerabilidade do sistema.

\subsection{Distribuição da vegetação nativa}

Para a identificação de áreas que possuem maior quantidade de vegetação nativa na região, o mapa digitalizado do Mapeamento e Inventário da Flora Nativa e dos Reflorestamentos de MG (SCOLFORO; CARVALHO, 2006) foi reclassificado, selecionando somente as fitofisionomias presentes na região, classificando-as como vegetação nativa. Todas as outras informações presentes no mapa foram classificadas como nos demais indicadores.

\subsection{Delimitação da proposta de Unidade de Conservação}

Na delimitação da Unidade de Conservação proposta, consideraram-se somente as classes de vulnerabilidade alta e muito alta presentes na região da Serra de Carrancas e Luminárias, por englobarem áreas de alta sensibilidade à ação antrópica e áreas de significativa relevância ecológica. Esta imagem foi reclassificada em três classes: 1 , 2 e não classificada. Pequenos grupos de pixels isolados formados devido às inúmeras fragmentações no entorno da serra foram retirados automaticamente. O mapa resultante foi então tratado com um filtro de maioria, permitindo uma melhor classificação dos limites do fragmento de maior relevância para o propósito de criação dos limites da proposta de Unidade de Conservação. O mapa vetorizado foi utilizado na delimitação, analisando-se o maior fragmento resultante do tratamento, assim como fatores ecológicos relevantes como a distância dos centros urbanos, a possibilidade de interconectividade entre fragmentos remanescentes e o isolamento parcial proporcionado pelas elevadas altitudes da serra. Assim, a delimitação manual da Unidade de Conservação foi necessária devido à falta de homogeneidade da maior área de vulnerabilidade alta e muito alta assim como os fatores ecológicos já listados, sendo considerado para esta delimitação o mapa final vetorizado, analisado conjuntamente com a distribuição dos fragmentos de vegetação nativa e sua possível ligação aos demais fragmentos relevantes à região.

\section{RESULTADOS E DISCUSSÃO}

\subsection{Vegetação nativa}

A delimitação da Unidade de Conservação proposta baseada na distribuição da vulnerabilidade natural permitiu identificar a região da Serra de Carrancas e Luminárias que contem áreas agrupadas classificadas como alta e muito alta vulnerabilidade natural, reunindo aspectos ecológicos de grande importância à conservação da microrregião (Figura 1).

\subsection{Caracterização da Unidade de Conservação}

A área proposta para criação da Unidade de conservação (Figura 2) possuiria uma área total de 65.318 ha, abrangendo oito municípios: Carrancas, Minduri, Itumirim, Lavras, Ingaí, Cruzília, Luminárias e Itutinga. Carrancas e Itutinga são os maiores detentores de área dentro desta proposta, englobando uma área de remanescente florestal significativo. A Unidade de Conservação proposta seria representada por aproximadamente 30.000 ha de vegetação nativa.

A Unidade de Conservação proposta apresenta remanescentes significativos das três fitofisionomias encontradas na região, Campos (21.844,30 ha), Floresta Estacional Semidecidual (7.064,00 ha) e Campos Rupestres (641,20 ha) (Figura 3). Em menor quantidade está a fitofisionomia Cerrado, com 3,5 ha, totalizando 29.553,00 ha de área de vegetação nativa inserida na proposta de Unidade de Conservação e 35.765,40 ha em área antropizada.

A avaliação dos remanescentes florestais na proposição da delimitação da Unidade de Conservação foi realizada com base na importância destes para a indicação do estado do ecossistema. A vegetação é considerada um dos indicadores biológicos mais robustos da condição do ecossistema, pois possuem distribuição mais estática do que as populações de animais, abrangendo os grandes grupos de espécies animais e a existência de fragmentos implica na conservação, mesmo que mínima, dos elementos físicos e biológicos exigidos (SMALLWOOD et al., 1998). 


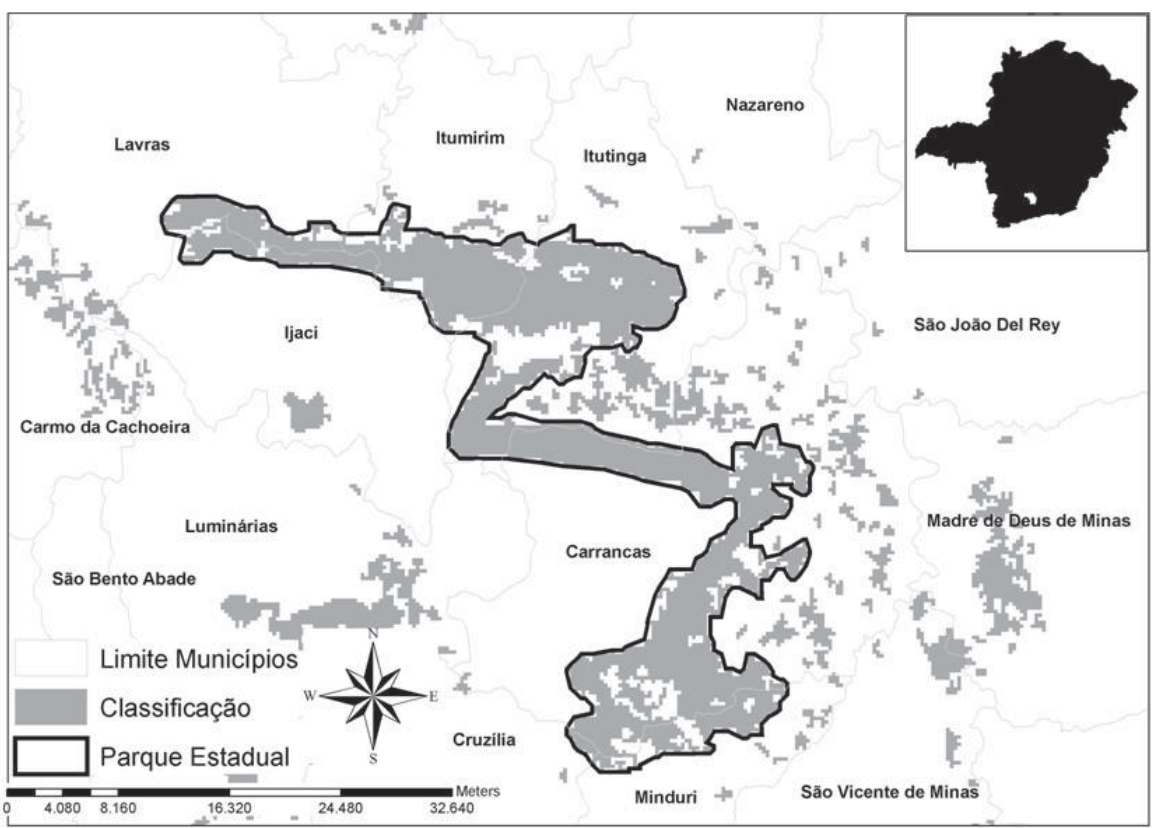

Figura 1 - Polígono resultante da avaliação de regiões agrupadas classificadas com vulnerabilidade alta e muito alta na microrregião da Serra de Carrancas e Luminárias, Minas Gerais.

Figure 1 - Resulting polygon from the assessment of grouped regions, according to high and very high vulnerability rating, in the Serra de Carrancas and Luminárias microregion, Minas Gerais.

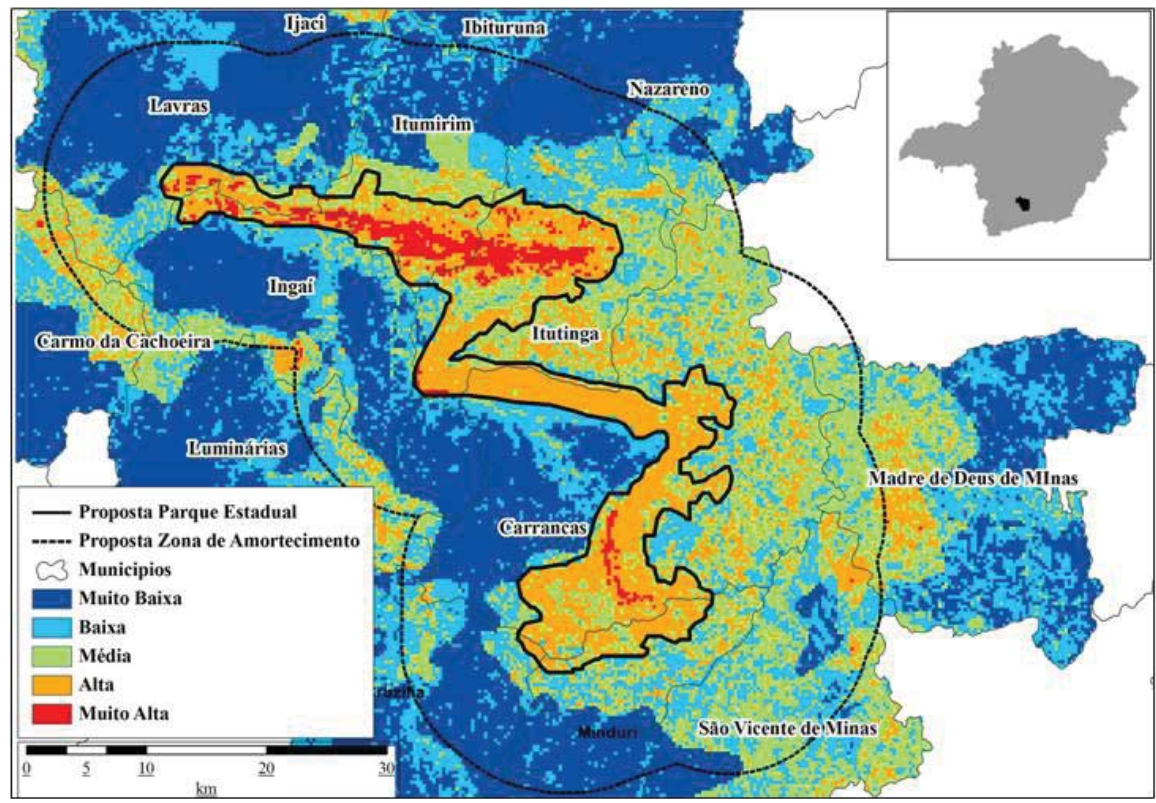

Figura 2 - Distribuição das classes de vulnerabilidade natural na microrregião da região da Serra de Carrancas e Luminárias, Minas Gerais, juntamente com a localização da proposta de Unidade de Conservação e da proposta de Zona de Amortecimento.

Figure 2 - Distribution of natural vulnerability classes in the Serra de Carrancas and Luminárias microregion, Minas Gerais, and location proposal for the Conservation Unit and Buffer Zone. 


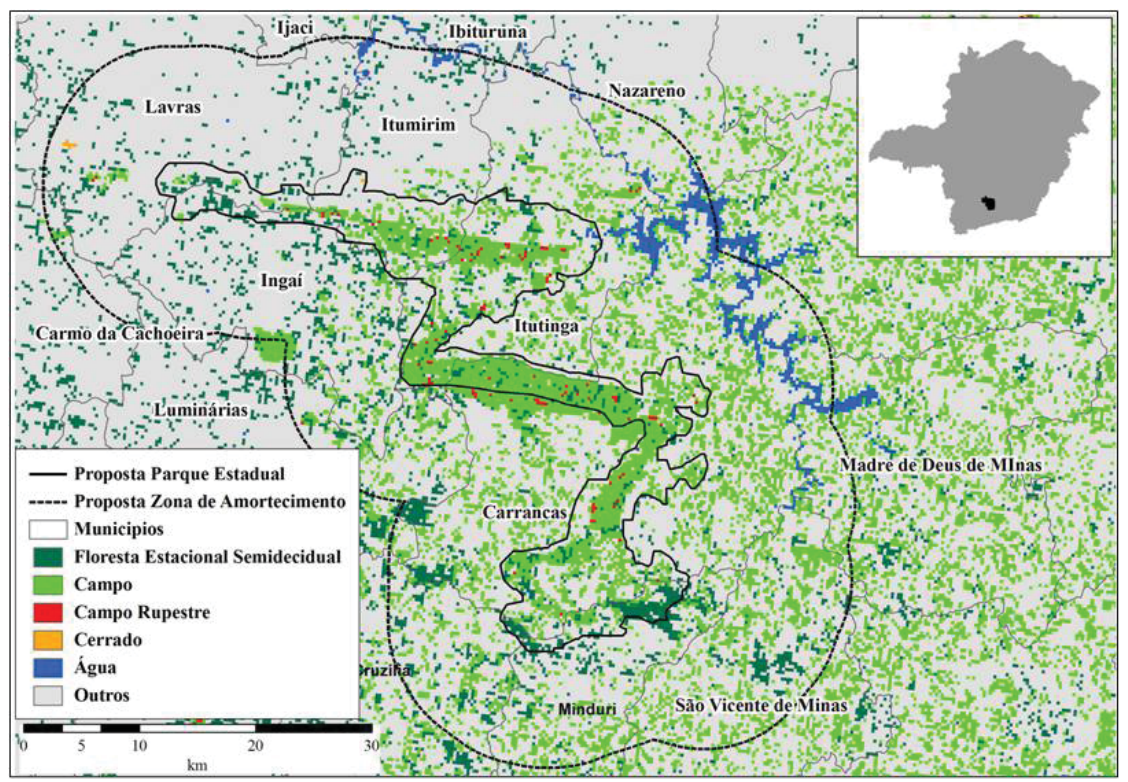

Figura 3 - Distribuição das fitofisionomias encontradas na microrregião do sul de Minas Gerais na proposta de criação da Unidade de Conservação na Serra de Carrancas e Luminárias.

Figure 3 - Distribution of phytophysiognomies found in the southern Minas Gerais microregion, according to the Conservation Unit creation proposal, in Serra de Carrancas and Luminárias.

Através do agrupamento de características físicas e bióticas na proposição de Unidades de Conservação, as ações de conservação e mitigação podem ser planejadas. O planejamento destas ações priorizando as partes da paisagem apóiam ou podem melhorar os elementos biológicos e físicos de maior valor para a função do ecossistema, que podem ser regulados pela estrutura da paisagem (SMALLWOOD et al., 1998).

\subsection{Distribuição da vulnerabilidade na área proposta para criação da Unidade de Conservação}

\subsubsection{Vulnerabilidade da fauna}

Dentro da proposta de criação de Unidade de Conservação, 25.719 ha de áreas são classificados com vulnerabilidade muito alta, distribuídos nos municípios de Lavras, Itumirim e Itutinga e áreas classificadas com vulnerabilidade alta estão presentes em 12.029 ha. Estas categorizações se devem, principalmente, à vulnerabilidade do indicador integridade de ictiofauna e de invertebrados. Vulnerabilidade média na integridade da fauna totalizam 11.300 ha, presentes nos municípios de Carrancas e Minduri. O presente estudo propõe a manutenção das espécies na microrregião da Serra de Carrancas e Luminárias através da avaliação do ecossistema em escala regional. A manutenção da biodiversidade de espécies está intimamente relacionada à indicação de áreas de conservação em grande escala e não somente para espécies ameaçadas (NOSS, 1991). Em alguns trabalhos, é apresentada a presença de espécies de animais no local de estudo, como em Almeida e Louzada (2009), que identificaram uma grande riqueza e abundância de espécies de Scarabaeidae, sendo algumas exclusivas da região, e em Pompeu et al. (2009) ,que identificaram diversas espécies de peixes na região, sendo a conservação da área um dos fatores que melhor explicaram a riqueza destas espécies.

\subsubsection{Vulnerabilidade da flora}

A Unidade de Conservação, de acordo com a vulnerabilidade da vegetação, englobaria áreas de maior concentração de vulnerabilidade muito alta e alta presentes na região, correspondendo a 3.157 ha com vulnerabilidade muito alta e 13.158 ha com vulnerabilidade alta. Todos os municípios presentes na proposta de Unidade de Conservação possuem regiões de vulnerabilidade muito alta e alta. Áreas de vulnerabilidade média correspondem a 11.300 ha e de baixa vulnerabilidade 12.029 ha. A vulnerabilidade alta e muito alta se devem à vulnerabilidade de indicadores como relevância regional das fitofisionomias, heterogeneidade de fitofisionomias e grau de conservação da flora. 


\subsubsection{Vulnerabilidade do solo}

A maior parte de todos os municípios presentes na proposta de Unidade de Conservação possuem vulnerabilidade muito alta e alta para este fator. Contornando a maioria das áreas de vulnerabilidade alta, com 40.970 ha e vulnerabilidade muito alta, com 20.871 ha, ocorrendo pequenas áreas de média vulnerabilidade, 320 ha. Áreas de baixa vulnerabilidade apresentam 1028 ha e muito baixa, 2.129 ha. Os indicadores que propiciaram esta classificação foram a compactação do solo e decomposição de matéria orgânica. Também são solos que possuem grande vulnerabilidade à contaminação e à erodibilidade.

\subsubsection{Vulnerabilidade à erosão}

Para o fator condicionante Vulnerabilidade à erosão, esta Unidade de Conservação Proposta englobou 7.392 ha com vulnerabilidade muito alta, 11.387 ha com alta vulnerabilidade, 34.613 ha com média vulnerabilidade, 11.854 ha com baixa vulnerabilidade e 73 ha com vulnerabilidade muito baixa.

A avaliação da vulnerabilidade à erosão e do solo indicam o estado atual dos fatores abióticos que estão intimamente associados aos fatores bióticos. Tais fatores devem ser protegidos, pois exercem papel essencial na conservação da diversidade biológica (DRUMMOND et al., 2005). A localização da área de estudo em uma região montana amplia a importância de sua conservação devido à fragilidade destes locais às ações antrópicas, pois são lugares vulneráveis aos processos erosivos acelerados, que ocasionam a perda de solo, hábitat e espécies (DRUMMOND et al., 2005). Entretanto, ambientes como os da serra de Carrancas/Luminárias também são importantes devido a características particulares, que os tornam reservatórios de biodiversidade e espécies endêmicas (MENDONÇA; LINS, 2000).

\subsection{Padrão geral de Vulnerabilidade Natural da Unidade de Conservação}

A proposição de Unidades de Conservação através da avaliação de regiões de alta vulnerabilidade juntamente com a distribuição dos remanescentes florestais naturais serve de subsídio às ações de conservação que, segundo Johnson (1995), devem apontar o que deve ser protegido, onde deve ser protegido e como deve ser protegido. Dentro do PE proposto, estão incluídas as maiores áreas (Figura 2), que estão classificadas como muito alta e alta vulnerabilidade natural presentes na microrregião, sendo pouco resistentes e pouco resilientes a ações que causam algum impacto ambiental. O município de Carrancas possui muito alta e principalmente alta vulnerabilidade natural, assim como parte dos municípios de Itutinga, Itumirim e Ingaí. As áreas de muito alta e alta vulnerabilidade natural correspondem a 5.701 ha e 33.730 ha, respectivamente.

Indicadores de estado do ecossistema precisam ser mensuráveis e quantificáveis com informações existentes (ADRIAANSE, 1993). Através da Vulnerabilidade Natural, é possível identificar áreas propícias à conservação dos recursos naturais, pois utiliza indicadores que determinam o estado atual do ecossistema.

A utilização da vulnerabilidade natural na indicação de áreas a serem conservadas permitem avaliar dados georreferenciados dos aspectos físicos e bióticos aumentando a eficiência na seleção de reservas. O aumento da eficiência é uma forma de minimizar os custos de conservação (NANTEL et al., 1998).

\subsection{Categorização da proposta Unidade de Conservação}

A proposta de Unidade de Conservação foi classificada dentro das categorias do Sistema Nacional de Unidades de Conservação (SNUC). O SNUC diferencia dois grupos de Unidades de Conservação: Unidade de Conservação de Proteção Integral e Unidade de Conservação de Uso Sustentável. Dentre os grupos, a proposta deste estudo foi indicada como de proteção integral, devido à localização em uma região de serra, grande parte abrangendo Áreas de Proteção Permanente, em ambientes naturalmente sensíveis à degradação. Dentre as categorias das Unidades de Proteção Integral, a criação de um Parque Ecológico abrange fatores relevantes à Serra de Carrancas e Luminárias. Fatores como a extensão da área proposta, alta relevância ecológica desta região, principalmente a localização em um ecótone dos biomas mata atlântica e cerrado, a possibilidade de desenvolvimento de atividades de educação ambiental, permitindo a integração da comunidade local na conservação da área. A relevância da microrregião estudada juntamente com a demanda de ações de conservação do governo do estado de Minas Gerais indicam a categoria de Parque Estadual como a principal forma de efetivar a conservação da região da Serra de Carrancas e Luminárias.

\subsection{Zona de Amortecimento}

Através da proposição do Parque Estadual foi possível traçar uma zona de amortecimento nas áreas circundantes da UC, num raio de $10 \mathrm{~km}$, onde as atividades humanas estarão sujeitas a normas e restrições específicas, 
com o propósito de minimizar os impactos negativos sobre a unidade. A criação de zonas de atividade restrita no entorno dos fragmentos florestais diminui a probabilidade de conversão destas áreas por atividade antrópicas (SMALLWOOD et al., 1998). Buscando integralizar as ações de conservação, a zona de amortecimento, na proposta de criação de um Parque Estadual, poderia pertencer a uma das categorias de Unidade de Conservação de Uso Sustentável.

\section{CONCLUSÕES}

A delimitação da área onde foi proposta a implantação de um Parque Estadual complementa a demanda apresentada pela Fundação Biodiversitas, da necessidade de criação de unidades de conservação na microrregião da Serra de Carrancas e Luminárias. A avaliação da vulnerabilidade natural desta região possibilitou identificar áreas classificadas como prioritárias à conservação, mas que não possuem remanescentes de vegetação nativa, resultando em vulnerabilidade baixa e muito baixa.

O Parque Estadual possuiria uma extensão de vegetação nativa de aproximadamente 30.000 ha, valor relativamente próximo à extensão de vegetação nativa da área prioritária que a Fundação Biodiversitas propôs, sendo que a extensão total da área prioritária possui uma extensão significativamente superior à área proposta para implantação do Parque (130.479 ha).

O estabelecimento de Unidades de Conservação focada na gestão da Vulnerabilidade Natural como apresentada garante uma melhor distribuição das indicações de ações a serem realizadas nestas áreas, com níveis variados de intervenção e proteção, assim como a sua conservação na forma de locais que garantam a permanência da biodiversidade de forma natural. A Vulnerabilidade Natural é um índice que permite delimitar áreas de baixa resiliência e resistência às ações antrópicas, considerando aspectos físicos e bióticos, indicando para estas áreas a conservação dos recursos naturais categorizadas de acordo com a relevância destes ambientes.

\section{REFERÊNCIAS}

ADRIAANSE, A. Environmental policy performance indicators: a study on the development of indicators for environmental policy in the Netherlands. Netherlands: SDU, 1993. 134 p.

Cerne, Lavras, v. 17, n. 2, p. 151-159, abr./jun. 2011
ALMEIDA, S. S. P.; LOUZADA, J. N. C. Estrutura da comunidade de scarabaeinae (Scarabaeidae: Coleoptera) em fitofisionomias do cerrado e sua importância para a conservação. Neotropical Entomology, Londrina, v. 38, n. 1, p. 32-43, 2009.

BURROUGH, P. A.; MCDONNELL, R. A. Principles of geographical information systems. Oxford: Oxford University, 1998. 193 p.

CARVALHO, D. A. Flora fanerogâmica de campos rupestres da Serra da Bocaina, Minas Gerais: caracterização e lista de espécies. Ciência e Prática, Belo Horizonte, v. 16, n. 1, p. 97-122, 1992.

CENTRO TECNOLÓGICO DE MINAS GERAIS. Mapa de solos de Minas Gerais. Belo Horizonte, 2006. 156 p. (Série de Publicações Técnicas).

DRUMMOND, G. M. (Org.). Biodiversidade em Minas Gerais: um atlas para sua conservação. Belo Horizonte: Biodiversitas, 2005. 222 p.

JOHNSON, N. Biodiversity in the balance: approaches to setting geographic conservation principles. Washington, 1995. $120 \mathrm{p}$.

MATSUMOTO, K.; MARTINS, A. B. Melastomataceae nas formações campestres do município de Carrancas, Minas Gerais. Hoehnea, São Paulo, v. 32, n. 3, p. 389-420, set. 2005.

MENDONÇA, M. P.; LINS, L. V. Lista vermelha das espécies ameaçadas de extinção da flora de Minas Gerais. Belo Horizonte: Fundação Biodiversitas, 2000. 157 p.

NANTEL, P.; BOUCHARD, A.; BROUILLET, L.; HAY, S. Selection of areas for protecting rare plants with integration of land use conflicts: a case study for the west coast of Newfoundland, Canada. Biological Conservation, Essex, v. 84, n. 3, p. 223-234, 1998.

NOSS, R. F. Sustainability and wilderness. Conservation Biology, Cambridge, v. 5, n. 1, p. 120-122, 1991.

OLIVEIRA-FILHO, A. T.; CARVALHO, D. A.; FONTES, M. A. L.; BERG, E. van den; CURI, N.; CARVALHO, W. A. C. Variações estruturais de compatimento arbóreo de uma floresta semidecídua alto-montana na Chapada das Perdizes, Carrancas, MG. Revista Brasileira de Botânica, São Paulo, v. 27, n. 2, p. 291-309, jun. 2004. 
OLIVEIRA-FILHO, A. T.; FLUMINHAN-FILHO, M.

Ecologia da vegetação do parque florestal Rio Bonito. Cerne, Lavras, v. 5, n. 2, p. 51-64, 1999.

POMPEU, P. S.; REIS, L. S.; GANDINI, C. V.; SOUZA, R. C. R.; FAVERO, J. M. The ichthyofauna of upper rio Capivari: defining conservation strategies based on the composition and distribution of fish species. Neotropical Ichthyology, Porto Alegre, v. 7, n. 4, p. 659-666, 2009.

SAMPLE, V. A. Remote sensing and GIS in ecosystem management. Washington: Island, 1994. 369 p.

SCOLFORO, J. R. et al. Zoneamento ecológico-econômico do Estado de Minas Gerais. Lavras: UFLA, 2008. 161 p.
SCOLFORO, J. R.; CARVALHO, L. M. T. Mapeamento e inventário da flora nativa e dos reflorestamentos de Minas Gerais. Lavras: UFLA, 2006. 288 p.

SMALLWOOD, K. S.; WILCOX, B.; LEIDY, R.; YARRIS, K. Indicators assessment for habitat conservation plan of Yolo county, California, USA. Environmental Management, New York, v. 22, n. 6, p. 947-958, 1998.

VASCONCELLOS, R. P. O uso do geoprocessamento para a quantificação de fragmentos naturais e mapeamento de áreas de preservação em Unidades de Conservação: estudo de caso da Mata Escura. 2002. 62 p. Monografia (Especialização em Geoprocessamento) - Universidade Federal de Minas Gerais, Belo Horizonte, 2002. 